\title{
Recreating Imagination and Self-Regulation as Means of Mathematical Thinking Development in Inclusive Education
}

\author{
Elvira G. Sabirova ${ }^{1 *}$, Zulfiya F. Zaripova ${ }^{2}$, Mikhail N. Mikhaylovsky ${ }^{3}$, Yulia V. Serebrennikova ${ }^{4}$, \\ Julia V. Torkunova ${ }^{5}$, Stanislav I. Buslaev ${ }^{6}$ \\ ${ }^{1}$ Kazan (Volga region) Federal University, Kazan, RUSSIA \\ ${ }^{2}$ Almetyevsk State Oil Institute, Almetyevsk, RUSSIA \\ ${ }^{3}$ I.M. Sechenov First Moscow Medical University (Sechenov University), Moscow, RUSSIA \\ ${ }^{4}$ Amur State University of Humanities and Pedagogy, Komsomolsk-on-Amur, RUSSIA \\ ${ }^{5}$ Kazan State Power Engineering University, Kazan, RUSSIA \\ ${ }^{6}$ Financial University under the Government of the Russian Federation, Moscow, RUSSIA
}

Received 20 March 2020 • Accepted 7 August 2020

\begin{abstract}
The relevance of this article is determined by the need to study new approaches to the organization of the study of mathematics in inclusive education, explore recreational imagination, as well as self-regulation for the development of the learners' ability to explain in detail their actions, find and correct mistakes on their own and thus develop their mathematical thinking. Today the needs of society to improve the quality of modern education along with the increasing volume of information that modern students must continuously process make the problem of developing mathematical thinking even more acute. The purpose of the study is to research the relationship between recreating imagination, mental self-regulation and mathematical thinking in students with mental retardation. Research methods included observation, psychological and pedagogical experiment, psychodiagnostic tests, and diagnostic tasks. Mathematical and statistical methods were also used (the Pearson correlation coefficient reflecting the degree of correlation between changes in two variables, where the changes in one of them correspond to the changes in the other), as well as interpretive methods. Research result: the article examines the relationship of mental self-regulation, recreating imagination and mathematical thinking in students with mental retardation and confirms the interrelationship of these processes using methods of mathematical statistics in psychology. It also discusses the complex of correctional and developmental exercises aimed at the development of recreating imagination and offers the means of developing mental self-regulation for the further development of the learners' mathematical abilities. The data obtained in this research can be used in social psychology, pedagogy, developmental psychology, inclusive education, as well as for further theoretical development of this area and find application in the broad practice of inclusive education together with an established and experienced system of tasks.
\end{abstract}

Keywords: inclusive education, mathematical thinking, mathematical abilities, recreating imagination, self-regulation

\section{INTRODUCTION}

In the last decade, the problems of children with disabilities have become the focus of the attention of an increasing number of professionals in various areas. One of the important areas in inclusive education is the development of learners' mathematical thinking. It is mathematical thinking that helps develop coherence and integrity of logical operations; students with developed mathematical thinking are able to keep a larger amount

(c) 2020 by the authors; licensee Modestum. This article is an open access article distributed under the terms and conditions of the Creative Commons Attribution License (http://creativecommons.org/licenses/by/4.0/). 


\section{Contribution to the literature}

- The article defines that for better development of mathematical thinking, it is important to develop learners' mental self-regulation, which facilitates the development of such mathematical thinking characteristics as flexibility, multidirectionality (easy restructuring of the line of thinking), and the ability to "see mathematical phenomena" in the observed reality.

- The authors have found that an important role in the qualitative development of mathematical thinking in learners is played by recreating imagination since its development facilitates the development of such characteristics of mathematical thinking as the desire to find a solution of a problem and obtain clarity without omitting individual elements in the chain of reasoning.

- It has been revealed for the first time that the effectiveness of the development of learners' mathematical thinking in the study of mathematics is subject to the development of self-regulation as the ability to explain their actions, find and correct mistakes on their own, the development of recreating imagination as the ability to learn, and positive motivation for the development of mathematical thinking.

- The article reveals that the existing methods of teaching in the reproductive learning model are not sufficient for the development of mathematical thinking: therefore, there is a need to change approaches to the organisation of the study of mathematics.

of information in memory, they realise that any problem has a solution and are able to split complex problems into smaller ones and identify correlations. Since mathematical thinking is closely related to spatial thinking, we can fairly assume that mathematical thinking can be developed by developing recreative imagination and self-regulation. The right to education is the most important social and cultural right of every person since education is the area of social activity that can most influence the development of individuals (Abasov, 1989; Begun \& Leikauf, 2001; Olkhovaya et al., 2019; Putilina et al., 2019). One of the objectives pursued by general secondary education in Russia is to develop a network of educational institutions for children with disabilities and those in need of psychological and pedagogical interventions. A child's personality is formed under the influence of all life circumstances (Golikov, 2006; Malofeev, 2010; Schmidt, 2006; YarskayaSmirnova, 1997). Currently, the contradictions have to be resolved between the need for pedagogical practice in the development of mathematical thinking and insufficient focus on this problem in pedagogy. In our opinion, this contradiction can be solved by developing the child's mathematical thinking through the development of self-regulation and recreating imagination. The term "children with special educational needs" can be also legally applied to children with disabilities, since in view of the limited opportunities of a person with psychophysical development issues to participate in the educational process such learners have special needs for specialised assistance in order to overcome these limitations. The term "children with special educational needs" has a broader content than the term "children with disabilities", since it also includes children with language barrier problems, difficulties in socialisation, and learning disabilities.
Mathematical thinking is a human mental activity that obeys mathematical laws, aimed at studying the world around us and establishing patterns of relationships between various objects and phenomena of reality (Bezuglov \& Litovchenko, 1997; Grebennikova \& Uvarova, 1998; Konobeeva, 2006; Shadrin, 2008; Vinogradova, 1989). In our opinion, by developing selfregulation in students, we will thereby facilitate the development of such characteristics of mathematical thinking as the child's desire to find a solution to the problem and obtain clarity without omitting individual elements in the chain of reasoning. By developing children's recreative imagination, we contribute to the development of such mathematical thinking characteristics as flexibility, multidirectionality (easy restructuring of the line of thinking), and the ability to "see mathematical phenomena" in the observed reality.

The relationships between various objects and phenomena can be comprehended with the help of recreating imagination as well as self-regulation understood as an awareness of rules, results, and modes of action. Mathematical thinking can be developed through the inclusion of students in the studies of mathematics, which is understood as a form of active learning of spatial concepts and quantitative correlations of the surrounding world by humans in order to transform and change them (Ivanova, 2002; Kalmykova, 1987; Yakimanskaya, 1989). The problem of selfregulation as an important structural element in the system of activity and behaviour is one of the main problems in psychology. Research on this topic is of great importance both for the theory of psychology and for public practice (Abulkhanova-Slavskaya, 1998; Cherdymova et al., 2019; Elkonin, 1994). Self-control and imagination are inherent in any human activity and are aimed at preventing or detecting mistakes that have already been made. Imagination takes people beyond the limits of their instantaneous existence, reminds them 
of the past and unveils the future. Recreating imagination is a type of active imagination in which new concepts are viewed by people subject to the perceived external stimulation in the form of verbal messages, diagrams, cosmetics, signs, and so on.

Mental self-regulation is a critical element of success in developing a child's mathematical thinking at school. The basic difficulty in teaching mathematics to children is not that they are not mentally developed to a sufficient extent or do not want to learn, but rather the fact that exploratory behaviour is not developed enough in them: children can not sit still in the classroom, they are constantly distracted while learning mathematics requires a strong focus on the subject. It is very difficult to teach and learn in this situation. Self-regulation manifests itself in different aspects of life, such as following the instructions of an adult, the ability to plan one's actions, compliance with the standards and rules of behaviour, ability to focus on something and bring it to its logical end, and the organisation of behaviour. That's why children with special needs (mental retardation) have difficulties in regulating their activity when studying mathematical disciplines that manifest themselves through losing some logical parts of the task that have been adopted at the beginning of a class, impaired ability to follow rules, failure to organise their activities, and the incompleteness of the validity of the result of the comparison with the given pattern. Imagination is an integral component of any form of human creative activity at all stages of life (Arnheim, 1974; Butkevich, 1983; Chistyakova, 1995; Strauning, 1992; Tunik, 2002).

\section{MATERIALS AND METHODS}

In order to identify the correlation between the level of mental self-regulation development, the level of recreating imagination development and mathematical thinking of primary school children with mental retardation, we used observation, psychological and pedagogical experiment, psychodiagnostic tests, and diagnostic tasks. In addition, mathematical and statistical methods were used (the Pearson correlation coefficient reflecting the degree of correlation between changes in two variables, where the changes in one of them correspond to the changes in the other), as well as interpretive methods.

Two groups of learners were involved in the experimental study. The reference group consisted of 18 children attending nursery school and the experimental group included 18 children of 6-7 years with mental retardation of a cerebral organic genesis.

In order to identify the relationship between mathematical thinking, on the one part, and imagination and mental self-regulation, on the other part, in primary school children with mental retardation, at the first stage, we used techniques to explore recreating imagination, self-regulation and mathematical thinking that facilitate the development of such mathematical thinking characteristics as flexibility, multidirectionality (easy restructuring of the line of thinking), and the ability to "see mathematical phenomena" in the observed reality. This study was conducted using the following methods: assessment of creative abilities of primary school children (an adapted version of Torrance Test); method of studying recreating imagination based on a fairy tale story for children; "Form a Sentence" method. The sequence of the presentation of the methods was based on the ontogenetic development of imagination. The evaluation criteria were originality of the drawings, the variety of characters in the story, and the emotionality of the representation. To assess the level of mathematical thinking development, group estimate criteria and levels were developed. Developing the learners' self-regulation with the use of such exercises as "Origami", "Missing Picture", and "What Is Missing", we will facilitate the development of such characteristics of mathematical thinking as the child's desire to find a solution to the problem and obtain clarity without omitting individual elements in the chain of reasoning.

To study mathematical thinking, children were offered tests that included logical and cause-and-effect relationships tasks, as well as tasks involving analysis and synthesis. Tasks were presented as a game: "Find an Extra Object", "Continue the Series", "Part-and-Whole", "Cause-and-Effect", "Simple-and-Complex". We used such game-like tasks, as it was easier for children to perceive them, and children were less tired in the process.

The educational experiment was conducted in three stages that had independent and always complex tasks. The introductory stage involved the development and selection of research methods and the development of methods aimed at the study of mathematical thinking. At the main stage, we conducted research and analysis of the results obtained in the course of diagnostics of selfregulation, recreating imagination and mathematical thinking. The final stage was dedicated to mathematical data processing and drawing up psychological and pedagogical recommendations.

\section{RESULTS}

According to the results of the study, $87.5 \%$ of primary school children with mental retardation have a below-average level of recreative imagination development. The drawings are similar to each other; peculiar features of the original are missing. The children depict one animal, or all three similar to each other, drawings are black and white, because the children use a lead pencil, as well as colorless, non-distinct, and sketchy.

This fact can result in a significantly lower level of coping with mathematical tasks in the future since 
successful completion of such mathematical tasks as "Part-and-Whole" and "Simple-and-Complex" requires a clear understanding and analysis of all the details. These children also encountered great difficulties when asked to come up with a story; they could not even tell a story about only one of their drawings. It will also affect the completion of the mathematical tasks, in particular, the ability to perform the "Cause-and-Effect" task. Only $12.5 \%$ of children in the experimental group and $25 \%$ of the reference group have shown an average level of the recreating imagination development; their drawings contain only some authentic elements; there are characteristic features of the original, but not in all the drawings. The children have managed to make up a story involving a single character. The majority of normally developing primary school children (89\%) have shown an above-average level of recreating imagination of development: their drawings are bright, multicolored, marked with a variety of characters. The drawings bear resemblance to the original. The children have managed to make up a story in which all three characters were involved.

In our opinion, this fact is an encouraging indication of success in performing mathematical tasks. Thus, the results obtained with the use of the method and the assessment of the creative abilities of primary school children show that primary school children with mental retardation have a below-average level of recreative imagination development. Their drawings are characterised by uniformity, inexpressiveness, and simplified characters; children can't make up a story. The majority of primary school children with mental retardation $(75 \%)$ have demonstrated a poor level of recreative imagination development. Almost $12.5 \%$ of children in the experimental group have drawn a standard rural house, without taking into account the circumstances described in the story. They see no figurative content behind the verbal description. This fact can be an alarming precursor to encountering difficulties when performing such mathematical tasks as "Part-and-Whole" and "Simple-and-Complex". There is no story behind the drawings, the representation is sketchy and colorless, and no new elements are added to the drawing. Only $12.5 \%$ of primary school children with mental retardation and $50 \%$ of normally developing primary school children have drawn a house of the original shape, but the drawing does not match the description.

The set of mathematical tasks requires precise execution of instructions and analysis of the proposed tasks in the form of drawings. Therefore, this fact can negatively affect the indicator of the mathematical thinking development level. There is a very simple story behind drawings, and the emotionality of the characters is hardly expressed. Half $(50 \%)$ of the surveyed children in the comparative group have demonstrated an aboveaverage level of recreating imagination: these children have drawn a non-standard, original image, there are a storyline and a sufficient number of extra wellelaborated characters, and the children's mood is reflected in the drawing. Thus, the results obtained with the use of the method indicate the presence of signs of the recreating imagination in primary school children. A low level of originality has been revealed: children draw an image far from the original or the image bears only slight resemblance to the original; there is a very little variety of characters and an unsophisticated storyline behind the drawings with a small number of additional characters, or the storyline is completely missing; the characters are marked with a little degree of emotionality or the lack of emotionality is observed.

The set of mathematical tasks offered to primary school children contains such an exercise as "Continue the Series" that is considered successfully completed if the child shows the ability to analyse and synthesise the existing components and parts and combine them into certain groups; however, poor level of accuracy in image reproduction may hinder this success. According to the results obtained using this method, $62.5 \%$ of children with mental retardation have been found to have a below-average level of the recreative imagination development and below-average verbal skills. Children struggle to make a story with the use of visual aids; they have been unable to make up sentences about all the proposed pictures at once, and rather come up with a sentence describing only one picture at a time. Just over a third of $37.5 \%$ of primary school children with mental retardation can only name the proposed pictures. In the reference group, $75 \%$ of children have managed to come up with several sentences about all the proposed images at once. Thus, the results obtained with the use of the method have revealed a low level of recreative imagination development in the speech of primary school children with mental retardation; children have failed to make up sentences using the pictures offered. In the course of the research with the use of the methods mentioned, a qualitative and quantitative assessment of children's mental self-regulation was carried out according to such criteria as acceptance of the task, ability to hold the task in memory, independence in performing the task, concentration during the task performance, and ability to stay involved.

Most of the primary school children with mental retardation $(62.5 \%)$ have shown a below-average level of mental self-regulation development. Children accept the task only after multiple explanations, keep only some of its components in memory to the end of the class, remember the task only in some cases, cannot perform the task on their own, often seek the help of an adult, can focus on a smaller part of the task and need external motivation to get involved in completing the task. $12.5 \%$ of children with mental retardation do not accept the task, or do it after repeated explanations and keep the task in memory for a short time. When performing a 
single task, they need constant guidance from an adult, and cannot concentrate on the task. Children constantly repeat the same questions.

The performance of math tasks will require a clear understanding of the instructions by a child. To avoid errors and omissions in mathematical tasks, we offered the children some test tasks to make sure that they understand the instructions.

$25 \%$ of children in the experimental group and $25 \%$ of children in the reference group have shown an average level of mental self-regulation development; they accept the task after repeated reminders, remember the problem statement in case of most tasks, occasionally seek the help of an adult, and get involved in the task performance slowly at first, and then faster. $75 \%$ of normally developing primary school children have demonstrated a high level of mental self-regulation development. Thus, primary school children with mental retardation demonstrate the following characteristics of mental self-regulation: difficulties in accepting and remembering tasks, inability to independently complete the task, focus only on a smaller part of the task, the need for external stimulation in order to get involved in completing the task, which in turn can negatively affect the ability to perform mathematical tasks offered to them in a form of a game following the "simple to complex" principle. According to the results of studying children with mental retardation, the following groups can be distinguished:

Group 1: do not accept the task or accept it after multiple explanations, remember the task for a short time only in some cases, need constant guidance from an adult, can not focus on the task and need external motivation to get involved in completing the task.

Group 2: accept the task only after multiple explanations, remember the task only in some cases, cannot perform the task on their own, often seek the help of an adult, can focus only on a smaller part of the task and need external motivation to get involved in completing the task.

Group 3: accept the task after repeated reminders, remember the task in case of most tasks, occasionally seek the help of an adult, can focus on most of the tasks, and get involved in the task performance slowly at first, and then faster.

In our opinion, all these three groups will significantly correlate with the level of mathematical thinking development, since the mathematical tasks require a certain degree of concentration, involvement, and understanding of instructions from the child.

Analysing the results of studying the recreating imagination and mental self-regulation development levels in the reference and experimental groups, we can draw the following conclusions. Primary school children with mental retardation have demonstrated such characteristics of recreating imagination as the similarity of images drawn, low level of originality, lack of diversity in drawings, moderate emotionality of images, or the drawings are marked with a reduced emotionality of characters; the children can not make up sentences based on the pictures offered. Psychical self-regulation of primary school children with mental retardation has such distinctive features as difficulties in accepting and remembering the task, inability to independently complete the task, focus only on a smaller part of the task, and the need for external stimulation in order to get involved in completing the task.

A comparative analysis of mathematical thinking development of children in two groups before the correctional exercises has revealed that normally developing primary school children with average and above-average levels of recreating imagination development and self-regulation have average and above-average levels of mathematical abilities, while children with mental retardation who have low, belowaverage and average levels of mental self-regulation and recreating imagination development, consequently show low, below-average and average levels of development of mathematical abilities.

A particular correlation is identified in such tasks aimed at studying mathematical thinking as "Part-andWhole", "Simple-and-Complex", and "Find an Extra Object".

The correlation between the processes of mental selfregulation, recreating imagination and mathematical abilities, which was revealed using the Pearson coefficient, is proved by the results of comparing the levels of development of these processes in each child with mental retardation and the experimental group as a whole.

Thus, it is assumed that by increasing the level of recreative imagination and self-regulation in the process of correctional work, we will simultaneously develop mathematical abilities.

\section{Correctional Work to Develop Mathematical Thinking}

Psychocorrectional classes were held twice a week in the period from October 2018 to April 2019. In total, 22 classes took place. The duration of each class did not exceed 30 minutes (according to age norms). There were 18 children in the group.

The correctional and developmental work was conducted following the "simple to complex" principle. The development of imagination was carried out using all types of the child's activities, such as games, drawings, and constructive activity. The set of used techniques included analogies, focusing attention, turning the unfamiliar into the familiar, inventing, and continuing the fairy tale.

Mathematical thinking was studied using methods similar to those used at the first stage of research. 
Table 1. The Pearson correlation coefficient (recreating imagination and mathematical thinking)

\begin{tabular}{lccccc}
\hline No. & $\mathbf{x}$ & $\mathbf{Y}$ & $\mathbf{X ~ y}$ & $\mathbf{x} \mathbf{x}$ & $\mathbf{y} \mathbf{y}$ \\
\hline 1 & 13 & 12 & 156 & 169 & 144 \\
2 & 16 & 16 & 256 & 256 & 256 \\
3 & 11 & 11 & 121 & 121 & 121 \\
4 & 11 & 12 & 132 & 121 & 144 \\
5 & 13 & 17 & 221 & 169 & 289 \\
6 & 7 & 10 & 70 & 49 & 100 \\
7 & 8 & 9 & 72 & 64 & 81 \\
8 & 12 & 11 & 132 & 121 & 144 \\
Total: & $\mathbf{9 1}$ & $\mathbf{9 8}$ & $\mathbf{1 , 1 6 0}$ & $\mathbf{1 , 0 7 0}$ & $\mathbf{1 , 2 7 9}$ \\
\hline
\end{tabular}

All methods aimed at the study of mathematical thinking were presented to primary school children in the form of a game to spark their interest in completing tasks. In addition, all mathematical tasks were offered following the "simple to complex" principle. There were two reasons for this: similarly, to make the children interested in completing tasks and to make it easier for children to understand what they had to do to perform the task.

Math tasks contained a "training part" to prevent the incorrect perception of instructions.

The correctional work aimed at the development of mental self-regulation and recreative imagination was held in several blocks, with each block consisting of propaedeutic, main and final stages. To achieve the objectives set, we have drawn up summaries of lessons and developed the content of a complex of correctional and developmental exercises for the development of recreative imagination and mental self-regulation of primary school students with mental retardation.

Each lesson had a certain purpose and structure; thus, the "Introduction" assumed greetings and warm-up, the "Main Part" included elements of art therapy and fairytale therapy, and the "Closure" assumed "Feedback". Upon completing the first block of correctional and developmental work, repeated diagnostics was carried out, which involved the following tasks: repeated diagnostics, analysis of the results obtained, evaluation of the level of mathematical thinking development and identification of a possible relationship between recreating imagination, self-regulation and the level of mathematical thinking development in primary school children.

The repeated diagnostics were carried out using methods similar to those used during the initial diagnostics, only the stimulus material was changed.

Analysing the results obtained in the course of the intermediate diagnostics, we can note an increase in the number of children who have shown an average level of recreative imagination development. This is manifested in the creation of an original image, where drawings are colored, bright, but do not correspond to the proposed description, and a simple storyline is present, as well as in an increase in the number of children who have shown an average level of mental self-regulation development.
This is also manifested in the fact that children remember the task in most cases, but accept the task after additional reminders, occasionally seek the help of an adult, and focus on most of the tasks.

After the second block of correctional and developmental work, a control experiment was conducted, the results of which demonstrated a higher level of mathematical abilities development in primary school children with mental retardation.

The Pearson correlation coefficient was calculated using the formula:

$$
\begin{aligned}
& r_{x y}=\frac{\left(x_{i}-x_{j}\right) \cdot\left(y_{i}-y_{j}\right)}{\sqrt{\left(x_{i}-x_{j}\right)^{2}\left(y_{i}-y_{j}\right)^{2}}} \\
& r_{x y}=\frac{(8 \cdot 1160)-(94 \cdot 98)}{0.71}
\end{aligned}
$$

The resulting value pertains to the zone of significance, which confirms the existence of a correlation between the level of development of recreating imagination and mathematical thinking (see Table 1). The correlation between the processes of mental self-regulation, recreating imagination and mathematical thinking, which has been revealed using the Pearson coefficient, is proved by the results of comparing the levels of development of these processes in each child with mental retardation and the experimental group as a whole.

\section{DISCUSSIONS}

Children with mental retardation demonstrate a gap in the development of mental self-regulation and recreating imagination, which in turn further complicates the development of mathematical thinking, since a number of characteristics associated with mathematical thinking develop slower, such as the child's desire to find a solution to the problem and obtain clarity without omitting individual elements in the chain of reasoning, flexibility, multidirectionality (easy restructuring of the line of thinking), and the ability to 
"see mathematical phenomena" in the observed reality. Thus, imagination is a particular form of reflection of the reality that consists of creating new ideas and images by a creative rethinking of existing ideas and concepts.

The development of mathematical thinking in children with mental retardation is subject to certain prerequisites: emotional communication with adults, subjective manipulation activity, and the need for different types of activities.

Primary school age is the age when the will develops as conscious control of an individual's behaviour, external and internal actions. In the process of learning and upbringing under the influence of the requirements of adults and peers, children develop an ability to subordinate their actions to certain tasks in order to achieve the goal and overcome arising difficulties.

Dependence on the field of perception, situation, or involuntary behaviour is the main obstacle to teaching mathematics to primary school children with mental retardation. Insufficient research on the problem of imagination and self-regulation of primary school children with mental retardation makes it impossible to form a comprehensive concept of the mathematical thinking development in this age.

\section{ACKNOWLEDGEMENTS}

1. The work is performed according to the Russian Government Program of Competitive Growth of Kazan Federal University.

2. The publication has been supported by the 'Russian Academic Excellence Project 5 - 100' of the I M Sechenov First Moscow State Medical University (Sechenov University).

3. The work is performed according to the Program of Development of Financial University under the Government of the Russian Federation for 2020.

\section{REFERENCES}

Abasov, E. A. (1989). Learning Activity of Schoolchildren. Soviet Pedagogy, 7, 40-43.

Abulkhanova-Slavskaya, K. A. (1989). Activity and Consciousness of the Individual as a Subject of Activity. Psychology of Personality in a Socialist Society. Moscow: Nauka Publishing House.

Arnheim. (1974). Art and Visual Perception. Moscow: Progress. https:/ / doi.org/10.2307/1572916

Begun, V., \& Leikauf, G. (2001). Education in Russia: Glossary. Moscow: Flinta Publishing House. Nauka.

Bezuglov, Yu. I., \& Litovchenko, N. G. (1997). Promoting Training in the Continuing Education System. Education as a Factor of Personal Development: Collection of Articles of Orenburg Teachers' Continuing Education Institute, 1, 75-81.
Butkevich, O. V. (1983). Beauty: Nature, Essence, Forms. Leningrad: Iskusstvo [Art] Publishing House.

Cherdymova, E. I., Ilkevich, T. G., Spirina, E. V., Blinov, L. V., Aliyev, H. K., Kukhtyaeva, E. A., \& Ivanshina, I. A. (2019). Physicality ecology: student attitude to their own body. Ekoloji, 28(107), 4925-4930.

Chistyakova, M. I. (1995). Psychogymnastics. Moscow: Prosveshcheniye.

Elkonin, D. B. (1994). Introduction to Developmental Psychology. Moscow: Rech Publishing House.

Golikov, N. (2006). Personal Assistance to a Disabled Child Attending a Mass Educational Institution. Uchitel, 1, 22-24.

Grebennikova, N. L. \& Uvarova, L. N. (1998). Organization of Primary Education Depending on Children's Readiness for School: (using mathematics materials). Sterlitamak: Sterlitamak State Pedagogical Institute.

Ivanova, Ye. O. (2002). Personality-Oriented Education: Individualising the Content of Education. Zavuch, 8, 100-115.

Kalmykova, Z. I. (1987). Productive Thinking as a Basis for Ability to Learn. Moscow: Pedagogica.

Konobeeva, T. A. (2006). Organization of the Process of Teaching Mathematics to First-Grade Pupils with a Glance to the Results of Pedagogical Diagnostics (PhD Thesis). Moscow: Moscow City Teachers' Training University.

Malofeev, N. N. (2010). Changes in Specialised Schools Are an Inevitable Global Process. Nizhegorodskoye Obrazovanije, 3, 4-9.

Olkhovaya, T. A., Cherdymova, E. I., Merculova, L. V., Manakova, O. S., Sukhodolova, E. M., Laptev, A. A., \& Popova, O. V. (2019). Development features of students communicative focus. Modern Journal of Language Teaching Methods, 9(1), 78-89.

Putilina, E. S., Meleshko, G. S., Cherdymova, E. I., Kurbanov, R. A., Belyalova, A. M., Shatskaya, I. I., Kobzeva, E. I., \& Zhuravleva, M. V. (2019). Ecological relationships in real and virtual environments: contact points. EurAsian Journal of BioSciences, 13(2), 1475-1480.

Schmidt, V. R. (2006). Social exclusion and inclusion in education: Educational and methodical manual. Moscow higher school of social and economic Sciences. Information and analytical portal Socpolitika.ru

Shadrin, V. Yu. (2008). Mathematical Giftedness of School Children as a Social and Pedagogical Phenomenon. The success of Modern Natural Science, 2, 68-69.

Strauning, A. M. (1992). Development of Creative Imagination in Preschool Children During Fine Arts Classes. Rostov-on-Don: Изд-во. 
Tunik, Ye. Ye. (2002). Psychodiagnostics of Creative Thinking: Creative Tests. Saint Petersburg: Peter.

Vinogradova, L. V. (1989). Development of Students' Thinking When Teaching Mathematics. Petrozavodsk: Karelia.
Yakimanskaya, M. (1989). Age-Specific and Individual Characteristics of Students' Creative Thinking. Moscow: Pedagogy.

Yarskaya-Smirnova, Ye. R. (1997). People with Disabilities. Russian Encyclopedia of Social Work, 1, 291-295.

\section{http://www.ejmste.com}

